\title{
Notes on Some Interesting Sporocarp-Inhabiting Fungi Isolated from Xylarialean Fungi in Japan
}

\author{
Wasiatus Sa'diyah ${ }^{1,2}$, Akira Hashimoto ${ }^{2, *}$, Gen Okada ${ }^{2}$ and Moriya Ohkuma ${ }^{1,2}$ \\ 1 Gradute School of Integrative and Global Majors, Tsukuba Life Science Innovation, University of Tsukuba, \\ 1-1-1 Tennodai, Tsukuba, Ibaraki 305-8572, Japan; wasiatusadiyah@gmail.com (W.S.); \\ mohkuma@riken.jp (M.O.) \\ 2 RIKEN BioResource Research Center, Microbe Division/Japan Collection of Microorganisms, 3-1-1 Koyadai, \\ Tsukuba, Ibaraki 305-0074, Japan; gokada@riken.jp \\ * Correspondence: akira.hashimoto@riken.jp; Tel.: +81-29-829-9106
}

Citation: Sa'diyah, W.; Hashimoto, A.; Okada, G.; Ohkuma, M. Notes on Some Interesting Sporocarp-Inhabiting Fungi Isolated from Xylarialean Fungi in Japan. Diversity 2021, 13, 574 https://doi.org/10.3390/d13110574

Academic Editors: Samantha

C. Karunarathna, Nakarin Suwannarach and Michael Wink

Received: 16 September 2021 Accepted: 5 November 2021 Published: 10 November 2021

Publisher's Note: MDPI stays neutral with regard to jurisdictional claims in published maps and institutional affiliations.

Copyright: (c) 2021 by the authors. Licensee MDPI, Basel, Switzerland. This article is an open access article distributed under the terms and conditions of the Creative Commons Attribution (CC BY) license (https:// creativecommons.org/licenses/by/ $4.0 /)$.

\begin{abstract}
The diversity of sporocarp-inhabiting fungi (SCIF) was examined using six samples of xylarialean fungi from two different forests in Ibaraki Prefecture, Japan: a moist forest in the Sakuragawa area and an urban dry forest in the Tsukuba area. These fungi were enumerated using direct observation and dilution plate methods. We obtained 44 isolates, and careful morphological and molecular phylogenetic studies of these isolates revealed that approximately $30 \%$ of the operating taxonomic units were undescribed or cryptic species related to known fungi. Although typical mycoparasitic fungi, such as helotialean fungi and Trichoderma spp., were not isolated, the genera Acremonium, Acrodontium, and Simplicillium were detected. Comparisons of SCIF communities between the two forests suggested that the number of isolated species in the Sakuragawa area was lower than that in the Tsukuba area. Soil-borne fungi, such as Aspergillus, Beauveria, Penicillium, and Talaromyces, or polypores/corticioid mushrooms, are frequently detected in the Tsukuba area. Factors affecting SCIF communities in the two forests are discussed. Some noteworthy fungi are briefly described with notes on taxonomy, ecology, and molecular phylogeny.
\end{abstract}

Keywords: DNA barcoding; environmental DNA; epiphyte; mycobiota; taxonomy

\section{Introduction}

Fungi are classified into one of the largest kingdoms in eukaryotes (i.e., kingdom Fungi) and are estimated to include more than 2.2 to 3.8 million species [1]. They are distributed worldwide and grow on a wide variety of substrates, such as soil, litter, living organisms (higher plants, algae, animals, fungi, lichens, etc.), house dust, and rock surfaces. Additionally, hidden underestimated diversity has been reported in unique niches, such as soda soils detected using a culture-independent method [2], deep-sea using direct DNA sequencing method [3]. Xerophiles, such as Aspergillus halophilicus and Wallemia sebi [4,5], thermophiles [6], and hyperparasites [7] were also reported in fungi.

Fungicolous fungi are also known to dominate a unique niche $[7,8]$. The term refers to species of fungi that are associated with other fungi and used even when the biological nature of the association and its trophic relationship are obscure $[8,9]$. These fungi have been studied intermittently by various researchers. Early studies of fungicolous fungi focused on mycoparasites growing on basidiocarps and ascocarps $[10,11]$. Acremonium/Verticilliumlike fungi from the old stromata of xylarialean fungi or the tissues of Puccinia sp. were previously reported [12-15], while fungicolous fungi occurring in mushrooms in Japan were detected previously [16]. Antagonists are different from mycoparasites in terminology on the other hand, studies on antagonistic fungi initially focused on pathogenic soil fungi using isolates from the same environment/substrate or stocked cultures in laboratories $[17,18]$ and then shifted to research on specific parasites and host fungi, such as Tilletiopsis on Sphaerotheca [19] and Trichoderma on Sclerotinia [20]. However, few studies have been 
conducted on the enumeration of fungi in fungal tissue. An early study of mycoflora on truffle sporocarps was reported by Marletto [21], who isolated yeasts and yeast-like fungi from the surface of Tuber spp. Studies of mycoflora in fungal tissue have focused on sequestrate fungi [22-24] or on sclerotium-forming fungi [25-28]. Recently, Obase et al. [29] obtained fungal isolates from the sclerotia of Cenococcum geophilum isolated in the USA and assigned them to 85 operational taxonomic units (OTUs) according to the sequences of nuclear internal transcribed spacer (ITS) and large subunit (LSU) rDNA regions. They mentioned that the identification of many fungal OTUs was challenging because most of them appeared to be distantly related to any described fungal species.

The term "sporocarp-inhabiting fungi (SCIF)" was used for fungicolous fungi that restricted to those existing on sporocarps of other fungi and trophic relationship with host has been widely recognized by Gams et al. [8]. In these habitats, unique phylogenetic groups of Hypocreales and Dothideomycetes were previously obtained. Although these previous studies were conducted under different research objects and methods, the results implied the existence of taxonomically interesting species or new lineages of SCIF. Most of these studies used sequestrate or sclerotium-forming fungi, and a few studies have been conducted on mycoflora on sporocarps above the ground.

The order Xylariales is a diverse group of ascomycetes, often associated with plants and is distributed worldwide [30]. Several mycoparasitic helotialean species have been reported to occur on the surface of ascomata or stromata of xylarialean fungi [8,31-34]. However, a survey of SCIF that do not sporulate on their hosts has not been conducted. In this study, we enumerated the SCIF mycobiota on xylarialean ascomata using direct observation and dilution plate methods.

\section{Materials and Methods}

\subsection{Field Sampling of Ascomata}

Xylariales ascomata were collected from two different forests in Ibaraki Prefecture, Japan: the Sakuragawa area on 16 August 2020 (sample nos. AM002, AM003, and AM007), and the Tsukuba area on 28 August 2020 (sample nos. WS34, WS35, and WS36) (Table 1), these fungal hosts were identified based on morphological features using references by Læssoe and Peterson [32] and Vasilyeva et al. [35]. Both sampling sites were typical secondary forests where Aucuba japonica, Cryptomeria japonica, Quercus serrata, and Zelkova serrata were dominant. The Sakuragawa area is a valley forest that is always in a moist environment. On the other hand, the Tsukuba area is an urban forest that is always in a dry environment. Fallen or trapped twigs on which xylarialean fungi (i.e., Annuloxypoxylon, Hypoxylon, and Nemania) grew on were collected at each site (Figure 1) to isolate SCIF. Samples were placed in a paper bag, transported back to the laboratory within the day, and kept in a refrigerator $\left(4^{\circ} \mathrm{C}\right)$. The isolation procedure of SCIF was performed within four days.

Table 1. List of samples from the moist forest (Sakuragawa area) and the urban dry forest (Tsukuba area).

\begin{tabular}{|c|c|c|c|}
\hline Sample No. & Species & Substrate & Sampling Site \\
\hline AM002 & Hypoxylon sp. & Cryptomeria japonica & $\begin{array}{l}\text { JAPAN, Ibaraki, Sakuragawa, near Ibaraki prefecture } \\
\text { road route } 41,36^{\circ} 14^{\prime} 26.195^{\prime \prime} \mathrm{N} 140^{\circ} 03^{\prime} 57.412^{\prime \prime} \mathrm{E}\end{array}$ \\
\hline AM003 & Hypoxylon sp. & Alnus sp. & $\begin{array}{c}\text { JAPAN, Ibaraki, Sakuragawa, near Ibaraki prefecture } \\
\text { road route } 41 \text {, dried river, } 36^{\circ} 14^{\prime} 54.103^{\prime \prime} \mathrm{N} \\
140^{\circ} 05^{\prime} 58.300^{\prime \prime} \mathrm{E}\end{array}$ \\
\hline AM007 & Nemania sp. & Cryptomeria japonica & $\begin{array}{l}\text { JAPAN, Ibaraki, Sakuragawa, around Ibaraki } \\
\text { prefecture road route } 41 \text {, near Onogawa-river, } \\
36^{\circ} 14^{\prime} 13.736^{\prime \prime} \mathrm{N} 140^{\circ} 06^{\prime} 05.799^{\prime \prime} \mathrm{E}\end{array}$ \\
\hline WS34 & Annulohypoxylon annulatum & Zelkova serrata & $\begin{array}{l}\text { JAPAN, Ibaraki, Tsukuba, near Takasaki Nature Park, } \\
\qquad 36^{\circ} 00^{\prime} 10.4^{\prime \prime} \text { N } 140^{\circ} 06^{\prime} 49.5^{\prime \prime} \mathrm{E}\end{array}$ \\
\hline WS35 & Nemania sp. & Zelkova serrata & $\begin{array}{c}\text { JAPAN, Ibaraki, Tsukuba, near Takasaki Nature Park, } \\
36^{\circ} 00^{\prime} 10.4^{\prime \prime} \mathrm{N} 140^{\circ} 06^{\prime} 49.5^{\prime \prime} \mathrm{E}\end{array}$ \\
\hline WS36 & Annulohypoxylon annulatum & Zelkova serrata & $\begin{array}{c}\text { JAPAN, Ibaraki, Tsukuba, near Takasaki Nature Park, } \\
36^{\circ} 00^{\prime} 10.4^{\prime \prime} \mathrm{N} 140^{\circ} 06^{\prime} 49.5^{\prime \prime} \mathrm{E}\end{array}$ \\
\hline
\end{tabular}



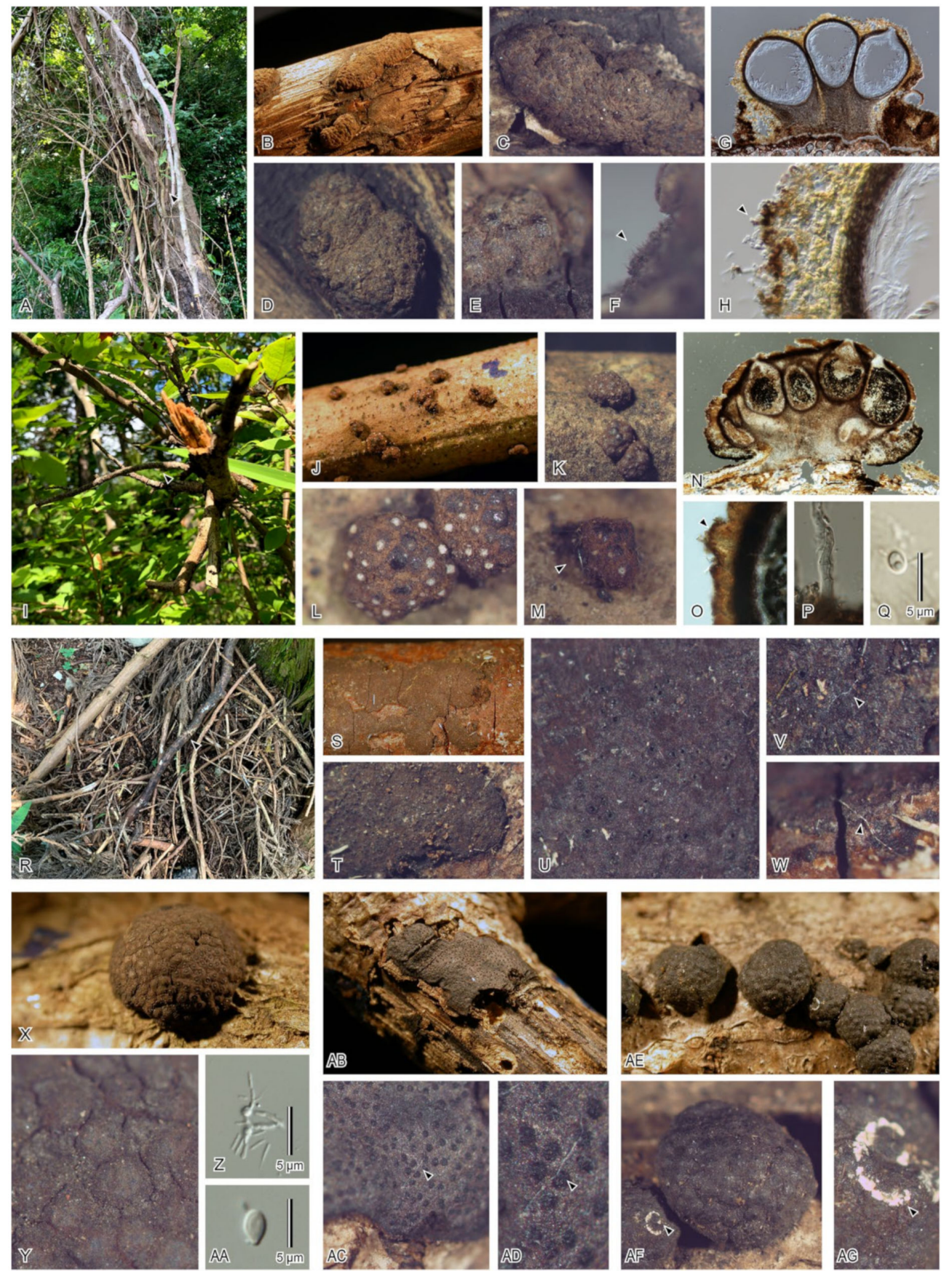

Figure 1. Habitats of the Xylariales fungi used in this study. (A-H) Field and microscopic observation of the sample AM002. (A) Habitat. Samples were collected from the trapped twigs (indicated by arrowhead). (B-F) Surface of the ascomata. SCIF occurring on the stroma in (F) (indicated by an arrowhead). (G) Ascomata in longitudinal section. (H) Melanized hyphae externally occurring on the host fungus peridium (indicated by an arrowhead). (I-Q) Field and microscopic observation of the sample AM003. (I) Habitat. Samples were collected from the dead twigs (indicated by an arrowhead). (J-M) Surface of the ascomata. SCIF occurring on the stroma in (M) (indicated by an arrowhead). (N) Ascomata in longitudinal section. (O) Melanized hyphae occurring on the peridium (indicated by arrowhead). (P) Sympodial conidiogenous cell occurring on the peridium. (Q) Unidentified conidium. (R-W) Field and microscopic observation of the sample AM007. (R) Habitat. Samples were collected from the fallen dead twigs (indicated by an arrowhead). (S-W) Surface of the ascomata. SCIF occurring on the stroma in $(\mathbf{V}, \mathbf{W})$ (indicated by an arrowhead). (X-AA) Microscopic observation of the sample WS34. (X-Y) Surface of the ascomata. (Z) Basidiospore of Ustilaginomycotina on the peridium. (AA) Acrodontium-type conidia on the peridium. (AB-AD) Microscopic observation of the sample WS35. Surface of the ascomata. SCIF occurring on the ascomata in (AC,AD) (indicated by the arrowhead). (AE-AG) Microscopic observation of the sample WS36. Surface of the ascomata. SCIF occurring on the ascomata in (AF,AG) (indicated by an arrowhead). 


\subsection{Isolation of SCIF}

Three small pieces of fungal tissues (ca. $2-3 \mathrm{~mm}^{3}$ ) from each sampled ascomata or stroma of Xylariales fungi was carefully cut using a sterile scalpel. These tissues were then submerged in $100 \mu \mathrm{L}$ of sterilized MilliQ (Merck, Darmstadt, Germany) and vortexed for ten minutes. The supernatant was diluted with sterile MilliQ at three concentrations (i.e., $10^{-3}, 10^{-4}$, and $10^{-5}$ ) and plated onto Yeast Malt Extract Agar consisting of $20 \mathrm{~g}$ of malt extract (Thermo Fisher Scientific, Detroit, MI, USA), $2 \mathrm{~g}$ of yeast extract (Becton, Dickinson and Company, Erembodegem, Belgium), $20 \mathrm{~g}$ of agar (Fujifilm Wako Pure Chemical Corporation, Tokyo, Japan), and $1000 \mathrm{~mL}$ of MilliQ with $0.05 \mathrm{~g} / \mathrm{L}$ chloramphenicol (Nacalai Tesque, Kyoto, Japan). The plates were incubated at $20 \pm 0.5^{\circ} \mathrm{C}$. The plates were examined regularly for three to seven days, and emerging fungal colonies were axenically transferred onto fresh potato dextrose agar (PDA; Becton, Dickinson, and Company, Sparks, MD, USA) plates for morphological observation and DNA extraction.

\subsection{DNA Extraction, Polymerase Chain Reaction (PCR) Amplification, and DNA Sequencing}

DNA was extracted from the cultures using a rapid preparation procedure for DNA extraction [36]. The internal transcribed spacer (ITS) was amplified using the primer pairs ITS5/ITS4 [37] and the large subunit nuclear ribosomal DNA (LSU) using the primer pairs LR0R/LR5 [38]. Alternatively, a primer set of V9G/LR5 [39] was used to amplify five isolates that failed using LR0R/LR5. A $25 \mu \mathrm{L}$ reaction mixtures that contained $3 \mu \mathrm{L}$ of MilliQ, $12.5 \mu \mathrm{L}$ of $5 \times$ buffer, $5 \mu \mathrm{L}$ of $2 \mathrm{mM}$ dNTPs, $1 \mu \mathrm{L}$ of each primer at $20 \mathrm{pM}$, and $0.5 \mu \mathrm{L}$ KOD FX Neo polymerase (TOYOBO, Tokyo, Japan) were prepared. Then, the PCR was carried out on a GeneAmp PCR System 9700 (Applied Biosystems, Foster City, CA, USA) as follows: initial denaturation at $94^{\circ} \mathrm{C}$ for $2 \mathrm{~min}$, followed by 38 cycles of $98^{\circ} \mathrm{C}$ for $10 \mathrm{~s} ; 61.5^{\circ} \mathrm{C}$ (ITS5/ITS4), $46{ }^{\circ} \mathrm{C}$ (LR05R/LR5), or $55^{\circ} \mathrm{C}$ (V9G/LR5) for $30 \mathrm{~s}$ of annealing, $68{ }^{\circ} \mathrm{C}$ for $1 \mathrm{~min}$ of extension, and $68^{\circ} \mathrm{C}$ for $7 \mathrm{~min}$ of final extension. The amplified PCR products were purified using ExoSAP-IT Express (Thermo Fisher Scientific) following the manufacturer's instructions. Purified DNA was sequenced using the BigDye Terminator v3.1 Cycle Sequencing Kit (Thermo Fisher Scientific) with the same primer pair for the ITS and LSU regions. Sequencing was performed on SeqStudio using default settings (Thermo Fisher Scientific). DNA sequences were manually assembled using ChromasPro version 2.1.8 (Technelysium Pty Ltd, Helensvale, Australia).

\subsection{Morphological Observation}

Eight isolates obtained from fungal substrates were prepared for microscopic morphological identification using the methods described by Zare et al. [14] with reference to Gams et al. [40]. Fungal structures were observed in preparations mounted using MilliQ. Field and macroscopic images were obtained using a X-M1 mirrorless digital camera (Fujifilm, Tokyo, Japan) with a QZ-35M lens (TAMRON, Saitama, Japan), a COOLPIX 4500 compact digital camera (Nikon, Tokyo, Japan), and a SMZ-10A stereomicroscope (Nikon) with a DP12 digital camera (Olympus, Tokyo, Japan). The morphological characteristics of the isolates were observed and recorded using an OPTIPHOT2 microscope with a differential interference contrast device and a DS-L2 digital camera (Nikon). To characterize colony morphology, PDA and 2\% malt extract agar (MEA; Becton, Dickinson, and Company) were used.

\subsection{Phylogenetic Analyses}

DNA sequences were compared using a megablast-search integrated into BLAST [41] based on the GenBank database (https: / / www.ncbi.nlm.nih.gov, accessed 18 October 2021). ITS sequences were used for ascomycetous isolates, and only a $98 \%-100 \%$ match with reliable sources (ex-type sequences or taxonomically validated sequences) was accepted as proof of identification, except for Eurotiomycetes genera Aspergillus, Penicillium, Taralomyces, and Dothideomycetes species Cladosporium cladosporioides complex sensu Bensch et al. [42]. LSU sequences were used for basidiomycetous isolates, and proof identification was conducted using the same criteria as ascomycetous fungi, except for Microporus, Sistotrema, and Trametes. Sequences were deposited in the DNA Data Bank of Japan (DDBJ; Table 2). 
Table 2. Identification of the isolated fungi in this study using BLAST.

\begin{tabular}{|c|c|c|c|c|c|}
\hline \multirow{2}{*}{ Sample No. } & \multirow{2}{*}{ Isolate No. (JCM No.) } & \multirow{2}{*}{ OTU Name } & \multirow{2}{*}{ Closest Match from GenBank Using Megablast } & \multicolumn{2}{|c|}{ GenBank No. } \\
\hline & & & & ITS & LSU \\
\hline \multirow[t]{5}{*}{ AM002 } & 1_1_B_As_1000 & Moesziomyces antarcticus & Moesziomyces antarcticus (MH873351) 822/822 (100.00\%) in LSU & LC631649 & LC631614 \\
\hline & 1_1_A_St_1000 & Herpotrichiellaceae sp. & “Capronia" pilosella (DQ826737) 535/542 (98.70\%) in ITS & LC631650 & LC631615 \\
\hline & 1_2_B_As_1000 & $\begin{array}{l}\text { Acrodontium sp. } 1 \text { aff. } \\
\text { crateriforme }\end{array}$ & Acrodontium crateriforme (NR_152320) $457 / 457$ (100\%) in ITS & LC631651 & LC631616 \\
\hline & 1_2_A_St_1000 & Tilletiopsis washingtonensis & Tilletiopsis washingtonensis (MH868275) 867/869 (99.77\%) in LSU & - & LC631617 \\
\hline & 1_8_A_St_1000 & Robbauera albescens & Robbauera albescens (MH873380) 809/810 (99.77\%) in LSU & - & LC631618 \\
\hline \multirow{2}{*}{ AM003 } & $\begin{array}{l}\text { 1_1_B_As_1000 } \\
\text { (=JCM 39226) }\end{array}$ & Acremonium sp. & Acremonium charticola (MH859034) 545/578(94.29\%) including 9 gaps in ITS & LC631653 & LC631620 \\
\hline & $\begin{array}{l}\text { 1_2_A_As_1000 } \\
(=\mathrm{JCM} 39227)\end{array}$ & Acremonium sp. & Acremonium charticola (MH859034) 557/590 (94.40\%) including 9 gaps in ITS & LC631654 & LC631621 \\
\hline \multirow[t]{4}{*}{ AM007 } & 2_1_A_As_1000 & Dactylospora sp. & Dactylospora parasitica (KY661666) 766/788(97.20\%) including 1 gap in LSU & - & LC631622 \\
\hline & 2_3_A_As_1000 & $\begin{array}{l}\text { Cladosporium sp. aff. } \\
\text { cladosporioides }\end{array}$ & Cladosporium cladosporioides complex sensu Bensch et al. [42] & LC631655 & LC631623 \\
\hline & $\begin{array}{l}\text { 2_4_A_As_1000 } \\
\text { (=JCM 39228) }\end{array}$ & $\begin{array}{l}\text { Acrodontium sp. } 3 \text { aff. } \\
\text { crateriforme }\end{array}$ & Acrodontium crateriforme (NR_152320) 441/442 (99.77\%) in ITS & LC631656 & LC631624 \\
\hline & 2_5_A_As_1000 & Skeletocutis odora & Skeletocutis odora (KY948893) 805/805 (100\%) in LSU & LC631657 & LC631625 \\
\hline \multirow[t]{13}{*}{ WS34 } & 1_2_A_As_10000 & Burgella sp. & Burgella flavoparmeliae (KC336075) 708/710 (99.72\%) in LSU & LC631658 & LC631626 \\
\hline & $\begin{array}{l}\text { 2_1_A_As_1000 } \\
(=\mathrm{JCM} 39229)\end{array}$ & Acrodontium cf. salmoneum & Acrodontium salmoneum (MH860376) 563/564 (99.82\%) including 1 gaps in ITS & LC631659 & LC631627 \\
\hline & 2_1_A_As_10000 & Penicillium sp. 1 & Penicillium citreosulfuratum (NR_153252) 576/578 (99.65\%) in ITS & LC631660 & LC631628 \\
\hline & 2_1_B_As_1000 & Sistotrema sp. aff. brinkmanni & Sistotrema brinkmannii-oblongisporum group sensu Moncalvo et al. [43] & LC631661 & LC631629 \\
\hline & 2_1_B_As_10000 & Acaromyces ingoldii & Acaromyces ingoldii (NG_058540) 445/446 (99\%) in LSU & LC631662 & LC631630 \\
\hline & $\begin{array}{l}\text { 2_2_A_As_10000 } \\
(=\mathrm{JCM} 39230)\end{array}$ & $\begin{array}{l}\text { Simplicillium sp. } 1 \text { aff. } \\
\text { sympodiophorum }\end{array}$ & Simplicillium sympodiophorum (NR_111027) 554/555 (99.82\%) in ITS & LC631663 & LC631631 \\
\hline & 2_2_A_As_1000 & Neoantrodiella gypsea & Neoantrodiella gypsea (KT203312) 773/774 (99.87\% in LSU & - & LC631632 \\
\hline & 2_2_B_As_1000 & Penicillium sp. 2 & Penicillium mallochii (NR_111674) 533/534 (99.81\%) including 1 gap in ITS & LC631664 & - \\
\hline & 2_2_B_As_10000 & Phlebia livida & Phlebia livida subsp. tuberculate (MW732462) 781/781 (100\%) in LSU & LC631665 & LC631633 \\
\hline & 2_3_A_As_10000 & Lenzites betulinus & Lenzites betulinus (MT644927) 785/785 (100\%) in LSU & LC631666 & LC631634 \\
\hline & 2_4_A_As_10000 & Microporus sp. aff. xanthopus & Microporus xanthopus (KX880659) 813/813 (100\%) in LSU & LC631667 & LC631635 \\
\hline & $\begin{array}{l}\text { 2_5_A_As_10000 } \\
(=\mathrm{JCM} 39231)\end{array}$ & Acrodontium luzulae & Acrodontium luzulae (NR_154720) 526/526 (100\%) in ITS & LC631668 & LC631636 \\
\hline & 3_1_A_As_10000 & Robbauera albescens & Robbauera albescens (NR_138401) 618/618 (100\%) in ITS & LC631669 & - \\
\hline
\end{tabular}


Table 2. Cont.

\begin{tabular}{|c|c|c|c|c|c|}
\hline \multirow{2}{*}{ Sample No. } & \multirow{2}{*}{ Isolate No. (JCM No.) } & \multirow{2}{*}{ OTU Name } & \multirow{2}{*}{ Closest Match from GenBank Using Megablast } & \multicolumn{2}{|c|}{ GenBank No. } \\
\hline & & & & ITS & LSU \\
\hline \multirow[t]{13}{*}{ WS35 } & 1_1_A_As_10000 & Robbauera albescens & Robbauera albescens (MH873380) 488/488 (100\%) in LSU & LC631670 & LC631637 \\
\hline & 1_2_A_As_10000 & Neoantrodiella gypsea & Neoantrodiella gypsea (KT203312) 750/750 (100\%) in LSU & LC631671 & LC631638 \\
\hline & 1_3_A_As_10000 & Incrustoporia chrysella & Incrustoporia chrysella (KP135286) 760/762 (99.74\%) in LSU & LC631672 & LC631639 \\
\hline & $\begin{array}{l}\text { 1_5_B_As_10000 } \\
\text { (=JCM 39232) }\end{array}$ & $\begin{array}{l}\text { Acrodontium sp. } 2 \text { aff. } \\
\text { crateriforme }\end{array}$ & Acrodontium neolitseae (NR_168148) 532/536 (99.25\%) in ITS & LC631673 & LC631640 \\
\hline & 2_1_B_As_1000 & Penicillium sp. 3 & Penicillium steckii (NR_111488) 373/373 (100\%) in ITS & LC631674 & - \\
\hline & 2_1_A_As_10000 & Trametes sp. aff. versicolor & Trametes versicolor (KC176306) 607/611 (99.35\%) in ITS & LC631675 & - \\
\hline & 2_2_B_As_10000 & Neoantrodiella gypsea & Neoantrodiella gypsea (KT203312) 670/671 (99.85\%) in LSU & LC631676 & LC631641 \\
\hline & 2_3_A_As_10000 & Neoantrodiella gypsea & Neoantrodiella gypsea (KT203291) 519/521 (99.62\%) including 1 gap in ITS & LC631677 & - \\
\hline & 2_4_B_As_1000 & Talaromyces sp. & Talaromyces aurantiacus (NR_103681) 464/474 (97.89\%) including 6 gaps in ITS & LC631678 & LC631642 \\
\hline & 2_6_B_As_1000 & Beauveria bassiana & Beauveria bassiana (NR_111594) 501/504 (99.40\%) including 1 gap in ITS & LC631679 & LC631643 \\
\hline & $\begin{array}{l}\text { 3_6_B_As_10000 } \\
\text { (=JCM 39233) }\end{array}$ & $\begin{array}{l}\text { Simplicillium sp. } 2 \text { aff. } \\
\text { sympodiophorum }\end{array}$ & $\begin{array}{c}\text { Simplicillium sympodiophorum (NR_111027) 559/561 (99.64\%) including } 1 \text { gap } \\
\text { in ITS }\end{array}$ & LC631680 & - \\
\hline & 2_4_B_As_1000 & Talaromyces sp. & Talaromyces aurantiacus (NR_103681) 464/474 (97.89\%) including 6 gaps in ITS & LC631678 & LC631642 \\
\hline & 3_8_B_As_10000 & Moesziomyces antarcticus & $\begin{array}{l}\text { Moesziomyces antarcticus (NR_155406) 686/689 (99.56\%) including } 2 \text { gaps in } \\
\text { ITS }\end{array}$ & LC631681 & - \\
\hline \multirow{5}{*}{ WS36 } & 1_2_B_As_10000 & Cerrena zonata & Cerrena zonata (MW785060) 711/712 (99.86\%) including 1 gap in LSU & LC631683 & LC631644 \\
\hline & 1_4_A_As_10000 & Sistotrema sp. & Sistotrema coroniferum (KF218968) 628/646 (97.21\%) including 4 gaps in LSU & LC631684 & LC631645 \\
\hline & 2_3_b_As_10000 & Neoantrodiella gypsea & Neoantrodiella gypsea (KT203312) 750/751 (99.87\%) including 1 gap in LSU & LC631685 & LC631646 \\
\hline & $\begin{array}{l}\text { 3_1_A_As_10000 } \\
(=\mathrm{JCM} 39234)\end{array}$ & Acrodontium luzulae & Acrodontium luzulae (NR_154720) 480/480 (100\%) in ITS & LC631686 & LC631647 \\
\hline & 3_3_A_As_1000 & Meira sp. & Meira miltonrushii (NG_060234) 470/472 (99.58\%) including 1 gap in LSU & - & LC631648 \\
\hline
\end{tabular}


To determine the novelty of the ascomycetous fungi, the candidates for new taxa were compared with those present in GenBank using the ITS and/or LSU sequences. Since several ITS sequences of environmental DNA and endophytic fungi that were deposited in GenBank were phylogenetically related to those of our samples, ITS data were used for alternative analysis. According to proof identification, known Acremonium, Acrodontium, and Simplicillium species were included in the alignment. Sequences for each dataset were aligned using MAFFT version 7.429 in the default setting [44]. Ambiguously aligned portions of the alignments were manually removed using MEGA7 [45]. A maximum-likelihood (ML) analysis was performed using IQ-TREE 2.1 [46] with 1000 standard nonparametric bootstrap replicates. The substitution model was estimated ModelFinder incorporated in IQ-TREE 2.1.

\section{Results}

\subsection{Field Sampling and Isolation}

Six samples were collected and identified from the two study areas (Table 1). Microscopic observations of the asexual structures of SCIF on Xylariales ascomata were as follows: ascomycetous fungi different from xylarialean fungi (Figure $1 \mathrm{~F}, \mathrm{H}, \mathrm{O}, \mathrm{P}$ ), unidentified-fungus conidium (Figure 1Q), Acrodontium-type conidium (Figure 1AA), Ustilaginomycotina (Figure 1Z), exogenous mycelium (Figure 1M,V,W,AC,AD), and mycelial structures suggestive of Polyporales basidiomycetes (Figure $1 \mathrm{AF}, \mathrm{AG}$ ).

A total of 139 isolates were obtained from the six ascomata. Of these, 12, 38, 7, 50, 26, and 6 isolates were obtained from AM002, AM003, AM007, WS34, WS35, and WS36, respectively (Table 2). Eighty-eight isolates with identical ITS sequences and/or the same colony characteristics within the same samples were excluded. Forty-four representative isolates were shown in Table 2. Sequencing of the ITS and LSU regions of the fungal isolates was performed, except for Dactylospora sp. and several Basidiomycota (Table 2). A BLAST search using the LSU or ITS sequences facilitated the genus-level identification of fungal isolates in many cases. The isolates belonged to six orders of Ascomycota (Chaetothyriales, Cladosporiales, Eurotiales, Hypocreales, Mycosphaerellales, and Sclerococcales) and eight of Basidomycota (Cantharellales, Corticiales, Entylomatales, Exobadisiales, Hymenochaetales, Polyporales, Robbauerales, and Ustilaginales) (Table 2). Some of the isolates (approximately 30\%) have not yet been identified or are unidentifiable at the species level; for example, Talaromyces sp., Penicillium sp. 1, Penicillium sp. 2, and Penicillium sp. 3 are unidentifiable due to lower identities (<98\% in ITS) with known species. Although the ITS sequence similarities were approximately 98-99\%, several species were treated as unidentified species as "sp." for Acremonium, or tentatively identified as Acrodontium sp. aff. crateriforme, and Simplicillium sp. aff. sympodiophorum or Acrodontium cf. salmoneum based on morphological observations (Figures 2-4). As a result, 33 different fungal OTUs were identified in this study (Table 2).

The fungal communities were compared between the two study sites. Acrodontium spp., Robbauera albescens, and Moesziomyces antarcticus were isolated from the Sakuragawa and Tsukuba areas. Acrodontium spp. and polypores or corticioid immature mushrooms (Neoantrodiella-like or Sistotrema-like) were detected in Tsukuba area. The species compositions showed a similar trend among the three isolated sources (WS34, WS35, and WS36) in this study area. For example, Neoantrodiella gypsea, Robbauera albescens, Simplicillium spp., and Sistotrema sp. were detected in at least two samples. Although the number of isolated species in the Sakuragawa area was lower than that in the Tsukuba area (10 spp. vs. 24 spp.), the species composition differed among samples. For example, Acremonium sp. was dominant in AM003, and few corticioid mushrooms (e.g., Sistotrema spp.) were detected among the three samples (AM002, AM003, and AM007). 

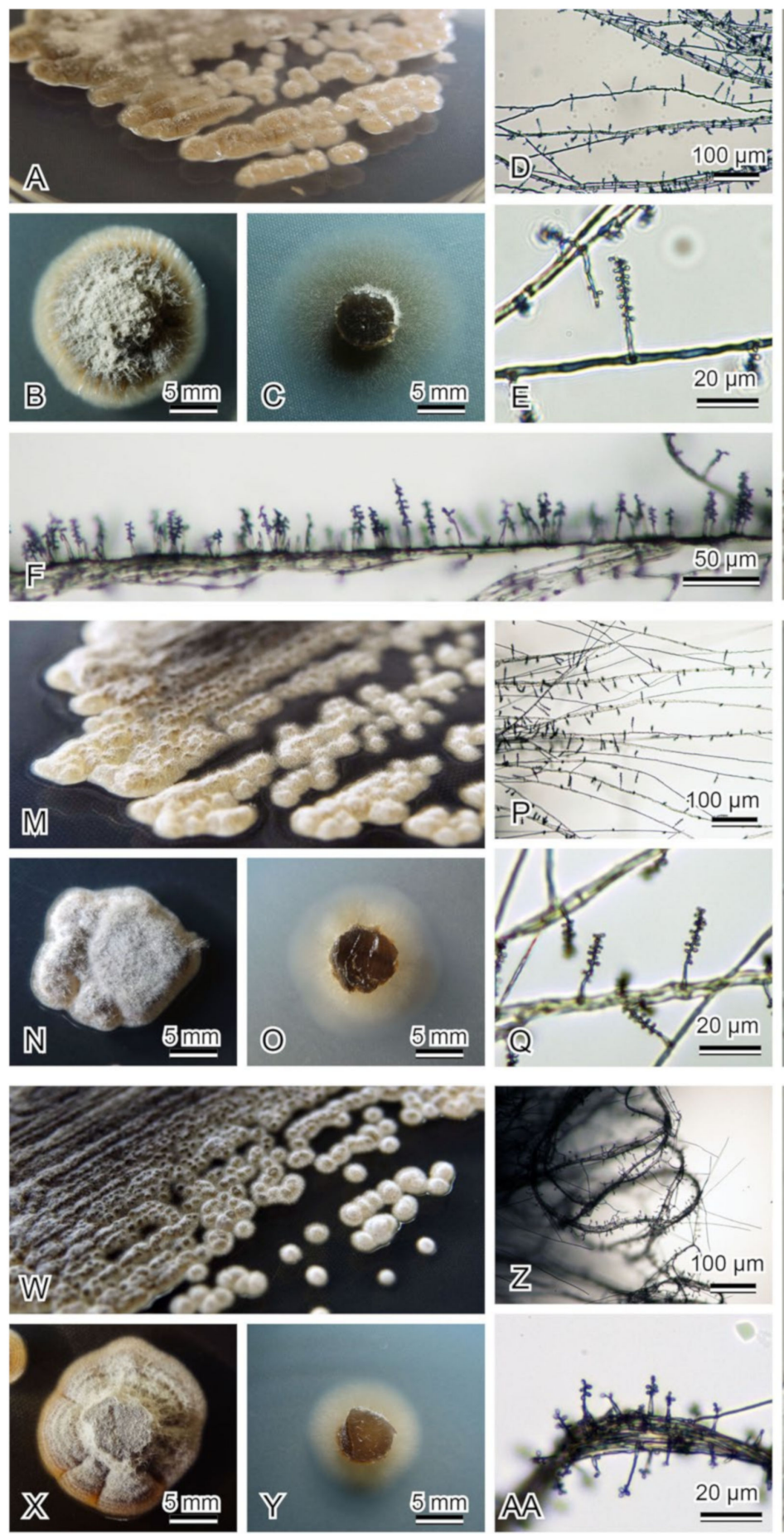
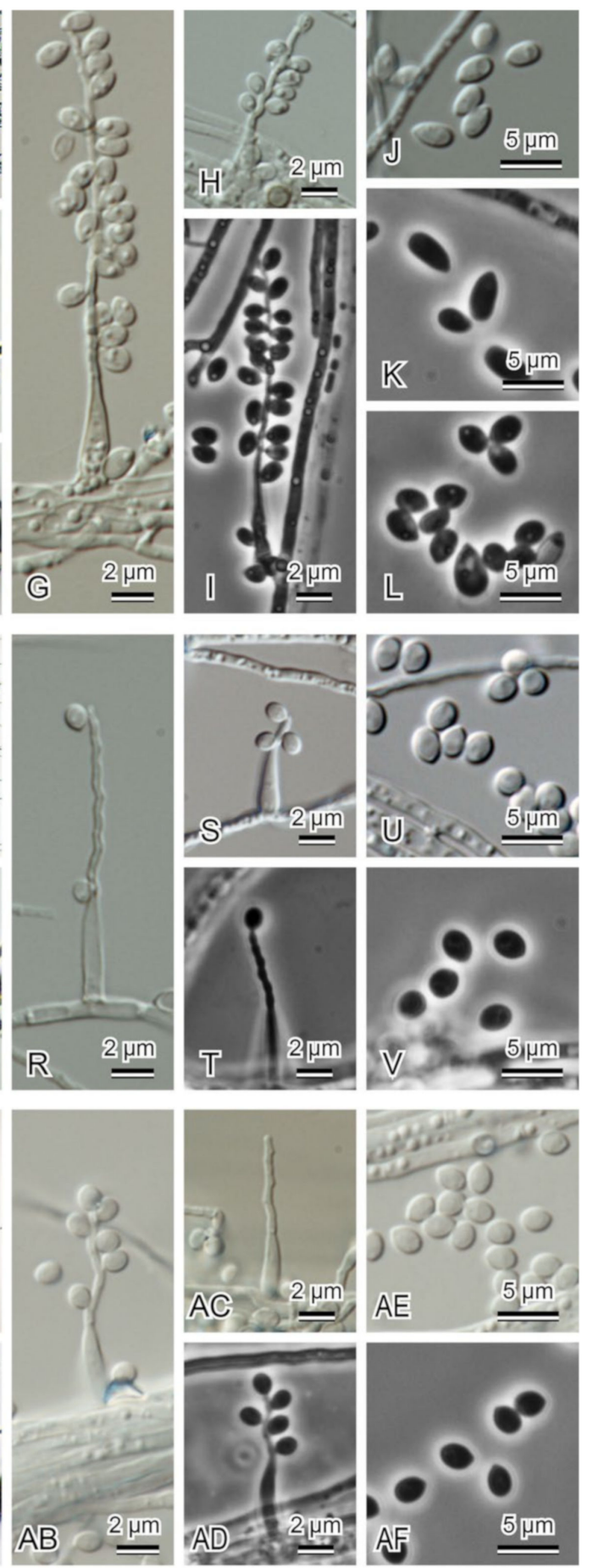

Figure 2. Acrodontium species. (A-L) Acrodontium luzulae (A-C,F,G,H,I,L from JCM 39231; D,E,J,K from JCM 39234). $(\mathbf{A}, \mathbf{B})$ Colonies on PDA after 8 days at $20^{\circ} \mathrm{C}$. (C) Colonies on MEA after 8 days at $20^{\circ} \mathrm{C}$. (D-F) Conidiogenous cells on hyphae. (G-I) Conidiogenous cells. (J-L) Conidia. (M-V) Acrodontium sp. 1 aff. crateriforme (JCM 39224). (M,N) Colonies on PDA after 8 days at $20^{\circ} \mathrm{C}$. (O) Colonies on MEA after 8 days at $20^{\circ} \mathrm{C}$. $(\mathbf{P}, \mathbf{Q})$ Conidiogenous cells on hyphae. (R-T) Conidiogenous cells. (U,V) Conidia. (W-AF) Acrodontium sp. 2 aff. crateriforme (JCM 39232). (W,X) Colonies on PDA after 8 days at $20^{\circ} \mathrm{C}$. (Y) Colonies on MEA after 8 days at $20^{\circ} \mathrm{C}$. $(\mathbf{Z}, \mathbf{A A})$ Conidiogenous cells on hyphae. (AB-AD) Conidiogenous cells. (AE,AF) Conidia. 

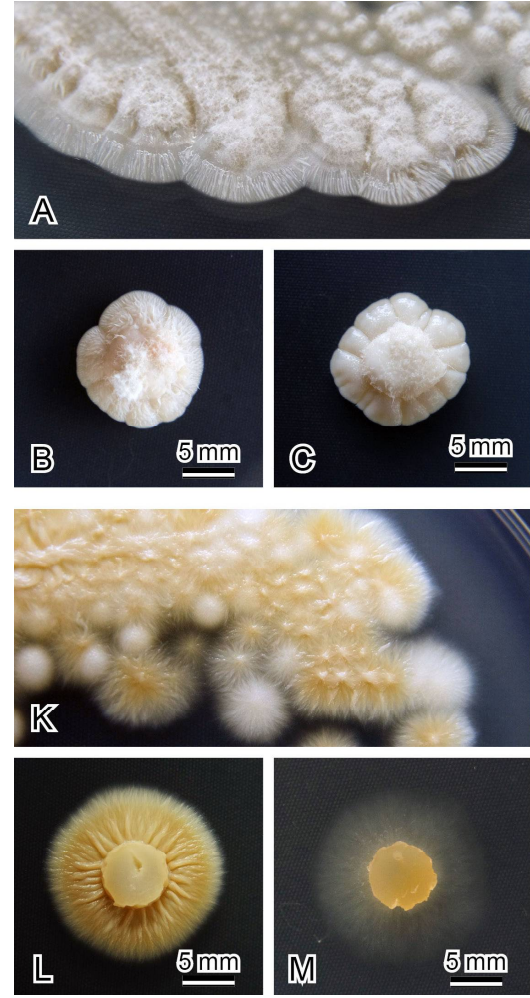
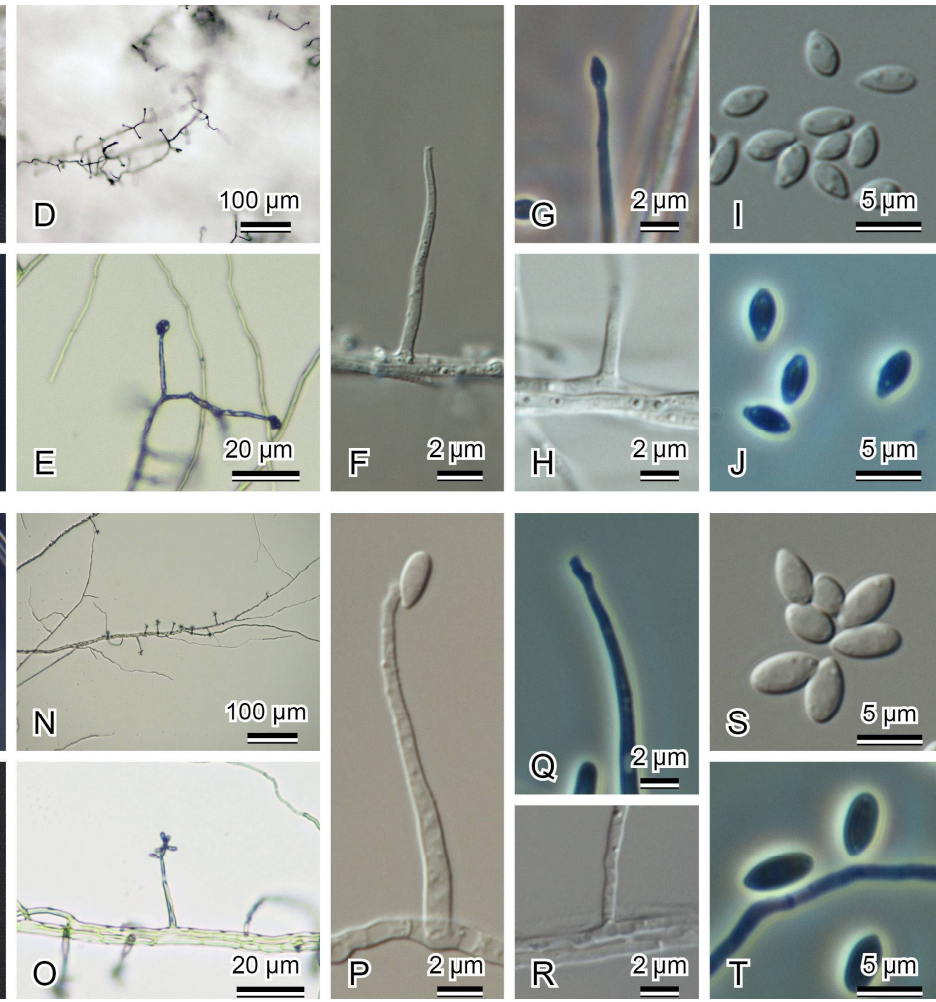

Figure 3. Acremoniunm sp. and "Acrodontium" cf. salmoneum. (A-J) Acremonium sp. (A,B from JCM 39226, C from JCM 39227, D-J from JCM 39225). (A-C) Colonies on PDA after 10 days at $28^{\circ}$ C. (D,E) Conidiogenous cells on hyphae. (F-H) Conidiogenous cells. (I,J) Conidia. (K-T) "Acrodontium" cf. salmoneum (JCM 39229). (K,L) Colonies on PDA after 8 days at $20^{\circ} \mathrm{C}$. $(\mathbf{M})$ Colonies on MEA after 8 days at $20^{\circ} \mathrm{C}$. $(\mathbf{N}, \mathbf{O})$ Conidiogenous cells on hyphae. (P-R) Conidiogenous cells. (S,T) Conidia.
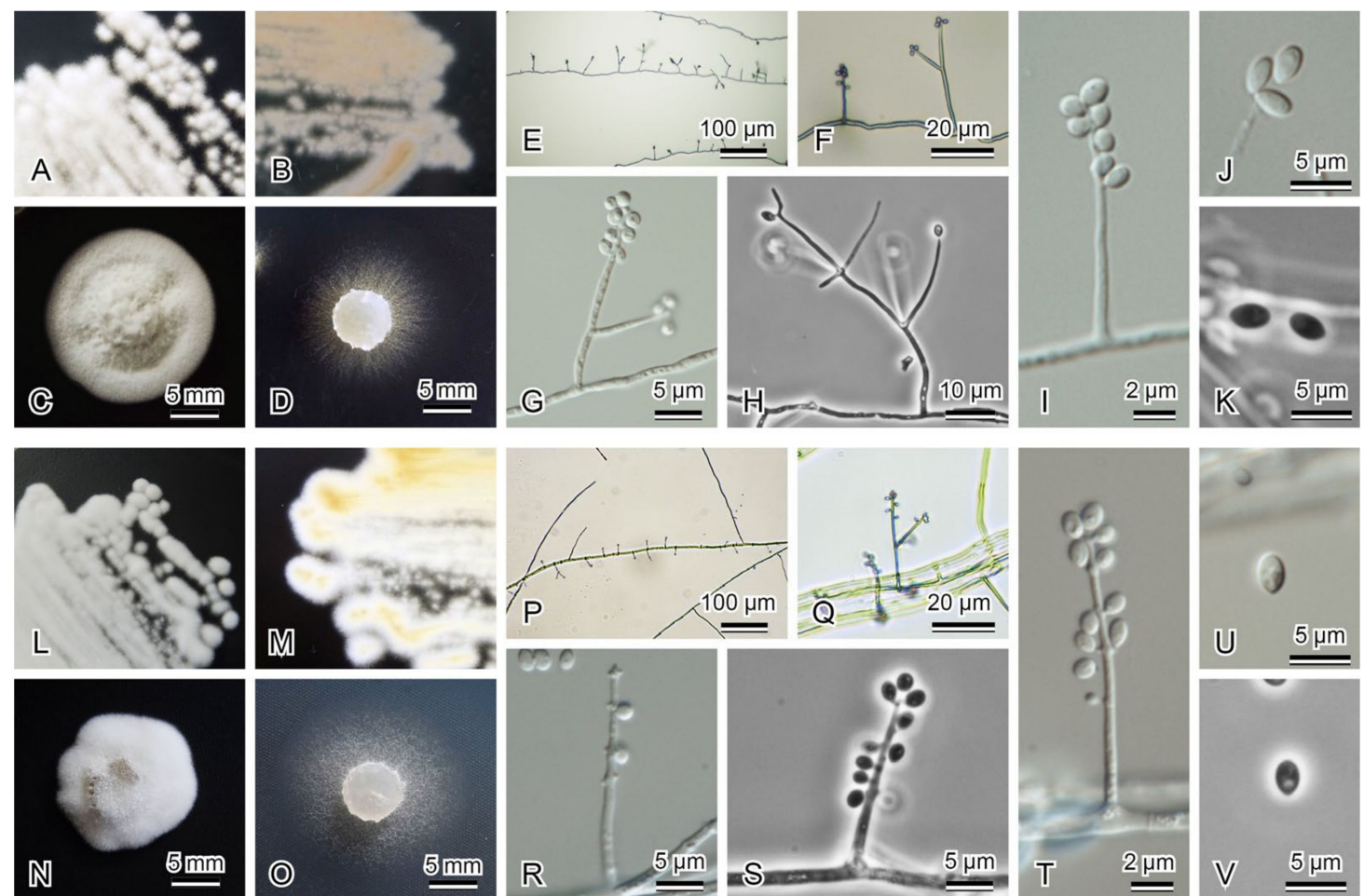

Figure 4. Simpllicillium species. (A-K) Simpllicillium sp. 1 aff. sympodiophorum (JCM 39230). (A-C) Colonies on PDA after 7 days at $25^{\circ} \mathrm{C}$. (D) Colonies on MEA after 7 days at $25^{\circ} \mathrm{C}$. (E-I) Conidiogenous cells. (J,K) Conidia. (L-V) Simpllicillium sp. 2 aff. sympodiophorum (JCM 39233). (L-N) Colonies on PDA after 7 days at $25^{\circ} \mathrm{C}$. (O) Colonies on MEA after 7 days at $25^{\circ} \mathrm{C}$. (P-T) Conidiogenous cells. (U,V) Conidia. 


\subsection{Morphological Observation and Molecular Phylogenetic Analyses of Noteworthy Fungal Species}

Noteworthy isolates were briefly described with phylogenetic analyses in this section, and some were deposited at the Japan Collection of Microorganisms (JCM), RIKEN BioResource Research Center, Tsukuba, Japan: cf., the JCM On-Line Catalogue of Strains (https://jcm.brc.riken.jp/en/catalogue_e, accessed on 18 October 2021).

Acrodontium luzulae Videira \& Crous (2016) (Figure 2A-L)

Strains examined: WS34_2_5_A_As_10000 (=JCM 39231); WS36_3_1_A_As_10000 (=JCM 39234).

Note: These isolates were identified as A. luzulae based on the conidial morphology as follows. Conidia hyaline, thin-walled, smooth, solitary, ellipsoid with obtuse apex, 2.8-5.3 $\times 1.6-2.4 \mu \mathrm{m}$ (av. $3.7 \times 1.8 \mu \mathrm{m}, n=55), 1 / \mathrm{w} 1.4-2.7(-3.3)$ (av. 2.1, $n=55)$. The ITS sequences of our isolates were identical to that of the ex-holotype strain of A. luzulae (CBS 839.71; KX287274) [47].

Acrodontium luzulae has been isolated from dead leaves of Luzula sylvatica and rust on Carex sp. [47,48] and dark ice [49] in previous studies. In this study, our isolates were collected from the old stroma of Annulohypoxylon annulatum, representing a new isolation record for this species. In addition, this is the first report of $A$. luzulae in Japan. Together with the previous literature data, it is possible to characterize $A$. luzulae as a cosmopolitan saprotrophic species of fungicolous fungi or plant decomposers.

\section{Acrodontium crateriforme complex}

Acrodontium crateriforme has been reported as a cosmopolitan species from invertebrate animals, fungi, humans, and plant tissues [47,48]. Koukol [50] highlighted that repeated isolation of A. crateriforme from invertebrates and fungi indicates a preference for more nitrogen-rich substrates. The author also pointed out that conidial size variations among strains obtained in previous studies $[47,48,50]$. In the present study, three isolates of this complex mentioned below were obtained from three different samples, and these isolates showed genetic and morphological variations (Figure 2M-AF and Figure 5). Further analysis based on additional gene regions, such as $r p b 2$ or $\beta$-tubulin [47], and the further discovery of additional strains will elucidate the diversity of their host preferences or their phylogenetic complexity.

Acrodontium sp. 1 aff. crateriforme (J.F.H. Beyma) de Hoog (1972) (Figure 2M-V)

Strain examined: AM002_1_2_B_As_1000 (=JCM 39224).

Note: Conidia in culture hyaline, thin-walled, smooth, solitary, spherical to oblong with obtuse apex, 2.4-3.1 × 1.5-1.7 $\mu \mathrm{m}$ (av. $2.6 \times 1.6 \mu \mathrm{m}, n=30$ ), $1 / \mathrm{w}$ 1.4-1.8 (av. 1.6, $n=30$ ). Although the ITS sequence of our isolate completely matched with that of the ex-holotype strain of $A$. crateriforme (CBS 144.33; NR_152320), the conidia of our isolate were slightly smaller than those of the ex-holotype strain [vs. (3-)3.5-4.5(-5) $\times(1.5-) 2-3(-4) \mu \mathrm{m}[48]]$. We treated this fungus as Acrodontium sp. 1 aff. crateriforme in this paper.

Acrodontium sp. 2 aff. crateriforme (J.F.H. Beyma) de Hoog (1972) (Figure 2W-AF)

Strain examined: WS35_1_5_B_As_10000 (=JCM 39232).

Note: The conidial features of our isolate were as follow. Conidia in culture hyaline, thin-walled, smooth, solitary, spherical to oblong with obtuse apex, 2-3.8 $\times 1.6-2.2 \mu \mathrm{m}$ (av. $2.7 \times 1.8 \mu \mathrm{m}, n=30$ ), 1/w 1.7-3.3 (av. 2.4, n=76). Although the isolate was closely related to the ex-holotype strain of $A$. crateriforme in the ITS region (Figure 5) with one nucleotide difference and no gap, it produced conidia slightly smaller than those of exholotype strain and broader than Acrodontium sp. 1 aff. crateriforme (vs. 1.5-1.7 $\mu \mathrm{m}$ wide in JCM 39224). We treated this fungus as Acrodontium sp. 2 aff. crateriforme in this paper. 


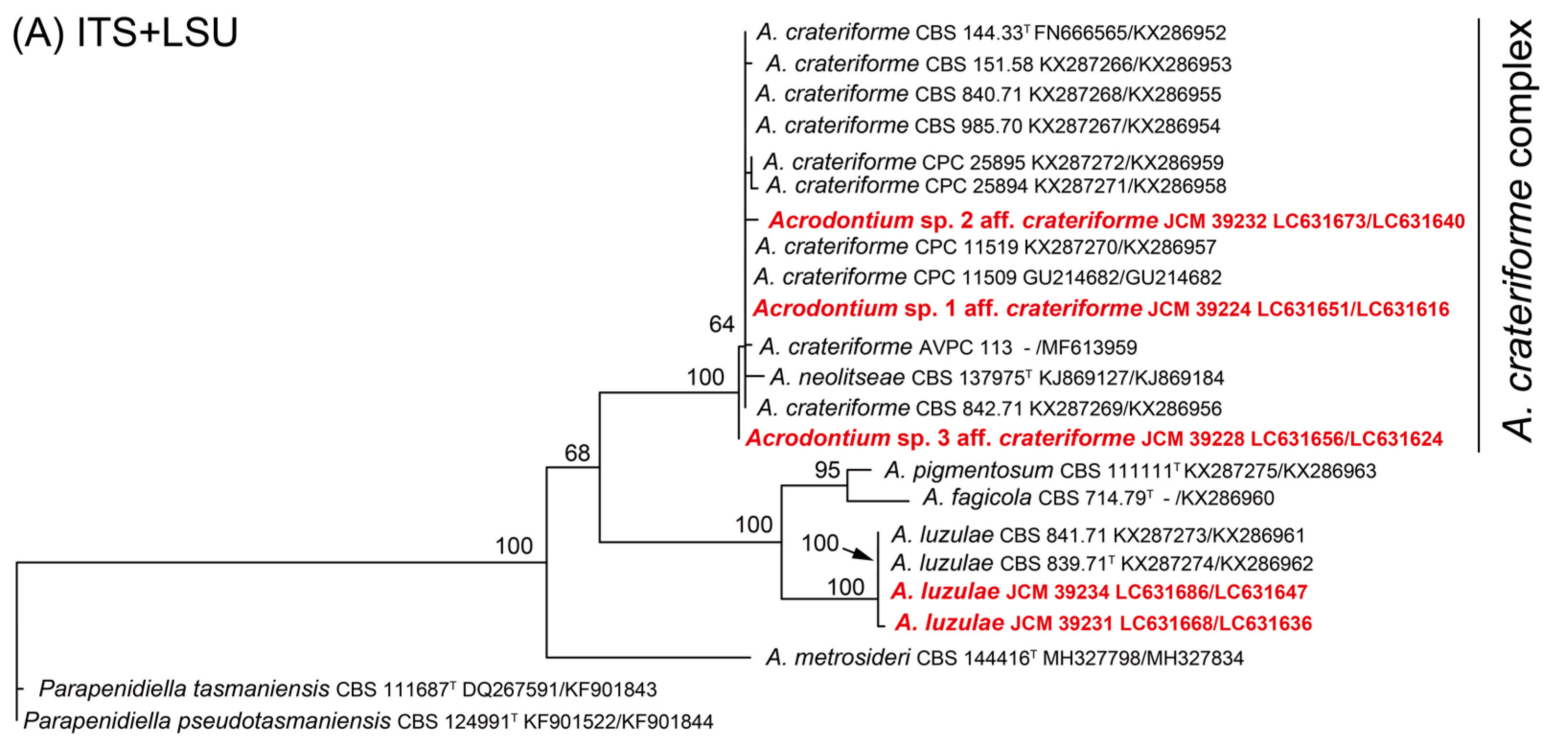

0.02

(B) ITS

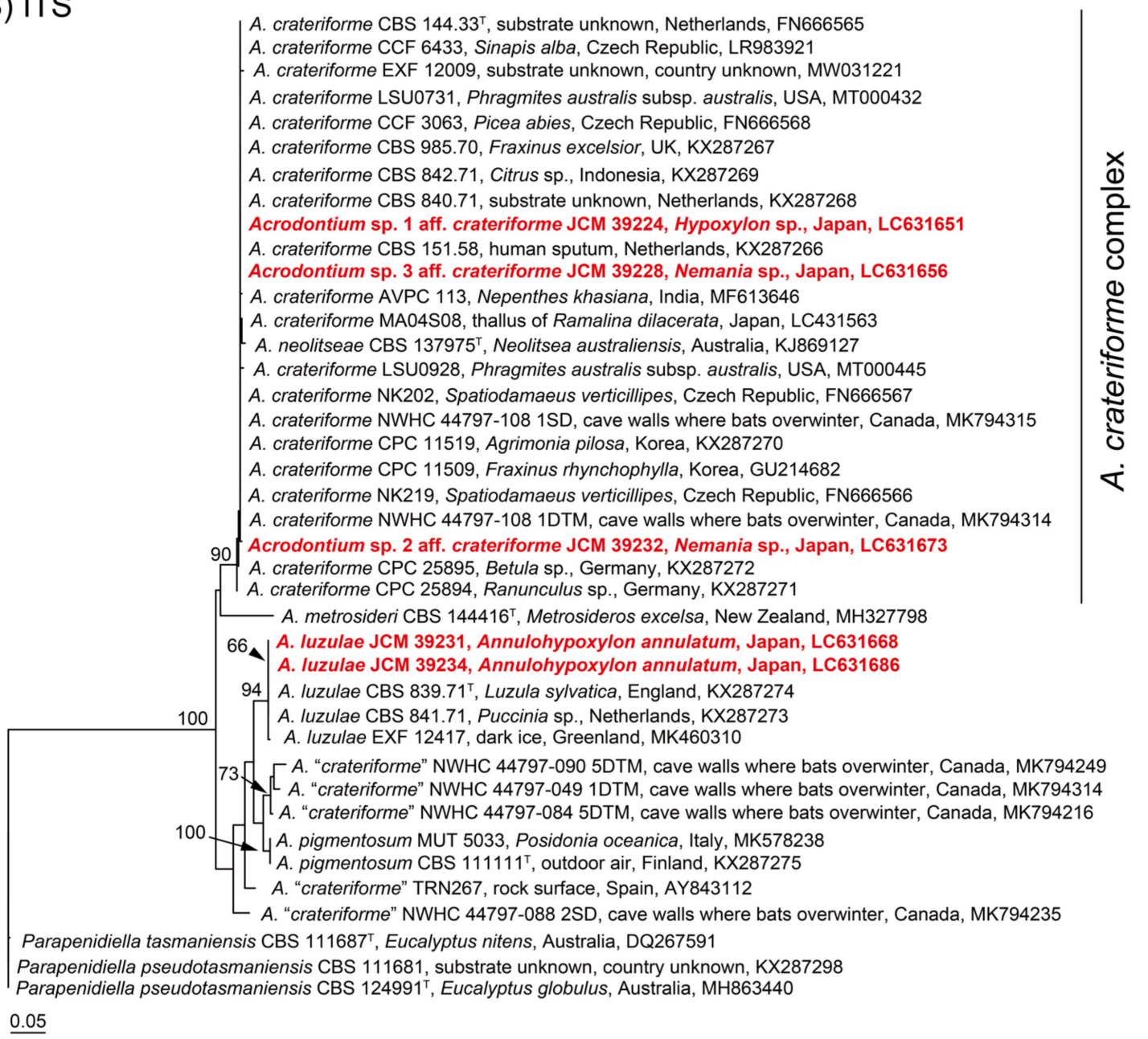

Figure 5. Maximum-likelihood (ML) tree of Acrodontium species. (A) Species relationship of Acrodontium by GTR $+\mathrm{F}$ model based on the ITS and LSU sequences. (B) Comparison of environmental samples with Acrodontium species by TIMe+R2 model based on the ITS sequences. Standard nonparametric bootstrap greater than or equal to $60 \%$ are presented at the nodes. Ex-type strains are indicated with a superscript T. The newly obtained sequences are shown in bold. The scale bar represents nucleotide substitution per site. 
Acrodontium sp. 3 aff. crateriforme (J.F.H. Beyma) de Hoog (1972)

Strain examined: AM007_2_4_A_As_1000 (=JCM 39228).

Note: In the phylogenetic tree, JCM 39228 clustered with the A. crateriforme complex (Figure 5). ITS sequences of our isolate and the ex-holotype strain of $A$. crateriforme (CBS 144.33; NR_152320) differed by one gap. The fungus differed from Acrodontium sp. 1 aff. crateriforme (JCM 39224) by one gap and Acrodontium sp. 2 aff. crateriforme (JCM 39232) by one nucleotide with one gap in the ITS region. We have not yet observed the morphological features in JCM 39228 very carefully, so we tentatively treated the fungus as Acrodontium sp. 3 aff. crateriforme according to the phylogenetic affinities.

Acremonium sp. (Figure 3A-J)

Strains examined: AM003_1_1_A_As_10000 (=JCM 39225); AM003_1_1_B_As_1000 (=JCM 39226); AM003_1_2_A_As_1000 (=JCM 39227).

Note: The morphological features of the above isolates were as follows. Conidiogenous cells arising from weakly fasciculate aerial hyphae, hyaline, thin-walled, smooth, ampulliform, tapering imperceptibly; conidia ellipsoidal, apiculate at both ends, 3.2-5.6 $\times 1.4-2.4 \mu \mathrm{m}$ (av. $4.1 \times 1.7 \mu \mathrm{m}, n=30$ ), 1/w 1-1.9 (av. 1.5, $n=30$ ), hyaline, smooth; chlamydospores absent. These features concurred with those of Acremonium section Acremonium sensu Gams [12].

Acremonium species are saprobic fungi that have been isolated from soil, air, and plant debris [51-53]. These species have been reported also as SCIF; e.g., from Psilocybe fasciata [54], Tuber [55], Xylariales fungi, and Puccinia sp. [12]. A BLAST search in the ITS region showed that our isolates were closely related to Acremonium charticola [CBS 117.25; MH854807, 453/489 (93\%, 5 gaps)]. The closest hits were five strains of unidentified fungal endophytes isolated from the leaves of tropical Fabaceae in Panama (Figure 6B). The ITS sequence of our isolates was identical or with 1-2 nucleotide differences and one gap. In the phylogenetic analysis, the three isolates grouped with Acremonium sclerotigenum clade sensu Summerbell et al. [56] (Figure 6A). Since we did not have additional isolates for detailed investigation, we treated this fungus as Acremonium sp. in this paper.

Acrodontium cf. salmoneum de Hoog (1972) (Figure 3K-T)

Strain examined: WS 34_2_1_A_As_1000 (=JCM 39229).

Note: The morphological features of the above isolate were as follows. Conidiogenous cells hyaline, thin-walled, cylindrical, straight to flexuous, proliferating sympodially and forming a rachis in the upper part, 36-58 $\mu \mathrm{m}$ long, and $0.6-0.9 \mu \mathrm{m}$ wide at apex, 1.6-3.2 $\mu \mathrm{m}$ at base, with multiple conidiogenous loci slightly thickened but not darkened; conidia hyaline, thin-walled, smooth, solitary, spherical to oblong with obtuse apex, 2.4-3.1 × 1.5-1.7 $\mu \mathrm{m}$ (av. $2.6 \times 1.6 \mu \mathrm{m}, n=30), 1 / \mathrm{w} 1.4-1.8$ (av. 1.6, $n=30$ ). This feature closely matched the description of Acrodontium salmoneum [48].

Acrodontium salmoneum and allied strains were isolated from various substrates. de Hoog [48] reported that the ex-holotype strain was isolated from human sputum (CBS 847.71) and three ex-paratype strains were originating from contaminant strains (CBS 580.67, CBS 846.71; NRRL Online Catalog, https:/ / nrrl.ncaur.usda.gov/, accessed 18 October 2021) and soil of beech forest (CBS 848.71). The fungus was also recorded in caves, mites, crab shells, and decayed wood in previous studies [48,57-59]. Phylogenetic analysis showed that our isolate grouped with the ex-paratype strains (CBS 580.67, CBS 848.71) and unidentified endophytic fungus (strain ZLY-2010 M29) from Abies beshanzuensis reported by Yuan et al. [60]. Although DNA sequence data suggested the possibility for cryptic species for these strains (3-19 nucleotide differences in the ITS region), no sequence data were available from the ex-holotype/ex-holotype strain of this species in GenBank (Accessed 18 October 2021). The conidia in our isolates were somewhat smaller than those of the original description [vs. (3.5-)4.5-5.5(-7) $\times(1.5-) 2-3(-3.5) \mu \mathrm{m}$ in de Hoog [48]]. Based on the phylogenetic and morphological differences, we treated this fungus as Acrodontium cf. salmoneum in this paper.

Videira et al. [47] suggested that A. salmoneum should be excluded from the genus Acrodontium because this species was phylogenetically separated from the type species of 
the genus based on the LSU sequence. However, its phylogenetic position has not been resolved in their study. The results of our phylogenetic analyses using LSU sequences suggested a close relationship of the "A. salmoneum" clade with Sarocladiacee (Figure 6A), but its generic placement for Acrodontium remains unresolved. Thus, we tentatively treated this species as "Acrodontium" salmoneum. Further isolates and sequences of the ex-holotype strain of $A$. salmoneum are needed to clarify the ecological aspects and generic position of the species.

\section{Simplicillium sympodiophorum complex}

Several species of Simplicillium have been reported as SCIF in a previous study [15]. Simplicillium sympodiophorum was originally isolated from soil under Asplenium antiquum at Aogashima, Izu Islands in Japan [61]. The species was later isolated from a fruit of Prunus avium [62] and from an arthropod Armadillidium vulgare [63]. In the present study, two isolates of this complex mentioned below were obtained from two different samples, and these isolates showed morphological variations (Figure 4). Most strains reported in previous studies were not unfortunately available for morphological comparison, but genetic variations were found in the ITS sequence (one to two nucleotide differences). At present, it is unclear whether these genetic variations implicate population or species differences.

Simplicillium sp. 1 aff. sympodiophorum Nonaka, Kaifuchi \& Masuma (2013) (Figure 4A-K)

Strain examined: WS34_2_2_A_As_10000 (=JCM 39230).

Note: The morphological features of our isolate were as follows. Conidiogenous cells are solitary or in whorls of 2-4, simple and slender, tapering toward the tip, 12-26.5 $\mu \mathrm{m}$ long, 0.4-0.8(-1.6) $\mu \mathrm{m}$ wide at apex, 0.8-1.6 $\mu \mathrm{m}$ at base; conidia 2.4-4.0 $\times 1.5-2.0 \mu \mathrm{m}$ (av. $3.0 \times 1.7 \mu \mathrm{m}, n=30$ ), 1/w 1.4-2.5 (av. 1.8, $n=30$ ). These features almost agreed with the description of $S$. sympodiophorum [61], although the length of conidiogenous cells was slightly shorter than that of the original description. The colony was slow-growing, reaching 13-18 mm diam. in 7 days at $25{ }^{\circ} \mathrm{C}$ on PDA, producing salmon pinkish pigment [vs. conidiogenous cells 20-34(-47) $\mu \mathrm{m}$ long; colonies 21-22 $\mathrm{mm}$ diam. in the same cultural condition, yellowish-white on surface, producing no water-soluble pigment in Nonaka et al. [61]]. The ITS sequence of our isolate showed only one nucleotide difference against S. sympodiophorum JCM 18184, ex-holotype (NR_111027), so we treated this fungus as Simplicillium sp. 1 aff. sympodiophorum.

Simplicillium sp. 2 aff. sympodiophorum Nonaka, Kaifuchi \& Masuma (2013) (Figure 4L-V)

Strain examined: WS35_3_6 B_10000 (=JCM 39233).

Note: The morphological features of the above isolate were as follows. Conidiogenous cells solitary or in whorls of $2-4$, simple and slender, tapering toward the tip, 17.5-28 $\mu \mathrm{m}$ long, $0.2-0.8 \mu \mathrm{m}$ wide at apex, $0.8-1.7 \mu \mathrm{m}$ at base; conidia oval to ellipsoidal, 2.4-3.0 × 1.6-2.0 $\mu \mathrm{m}$ (av. $2.6 \times 1.8 \mu \mathrm{m}, n=15), 1 / \mathrm{w} 1.2-1.9$ (av. 1.5, $n=15)$, smooth-walled, and one-celled. The morphological features were similar to those of S. sympodiophorum, but this isolate had slightly shorter and broader conidia than those of $S$. sympodiophorum (vs. 2.2-3.5 $\times 1.0-2.0 \mu \mathrm{m}$ in Nonaka et al. [61]). Simplicillium sp. 2 aff. sympodiophorum is similar to Simplicillium sp. 1 aff. sympodiophorum in conidial size, but could be distinguished by slightly slender conidia (vs. 2.4-4.0 × 1.5-2.0 $\mu \mathrm{m}$ ). This fungus produced yellowish pigment on PDA (Figure 4M), while Simplicillium sp. 1 aff. sympodiophorum produced pinkish one (Figure 4B). In addition, one nucleotide difference with one gap in the ITS region was found between Simplicillium sp. 2 aff. sympodiophorum and Simplicillium sp. 1 aff. sympodiophorum (JCM 39230). We treated this fungus (JCM 39233) as Simplicillium sp. 2 aff. sympodiophorum in this paper. 

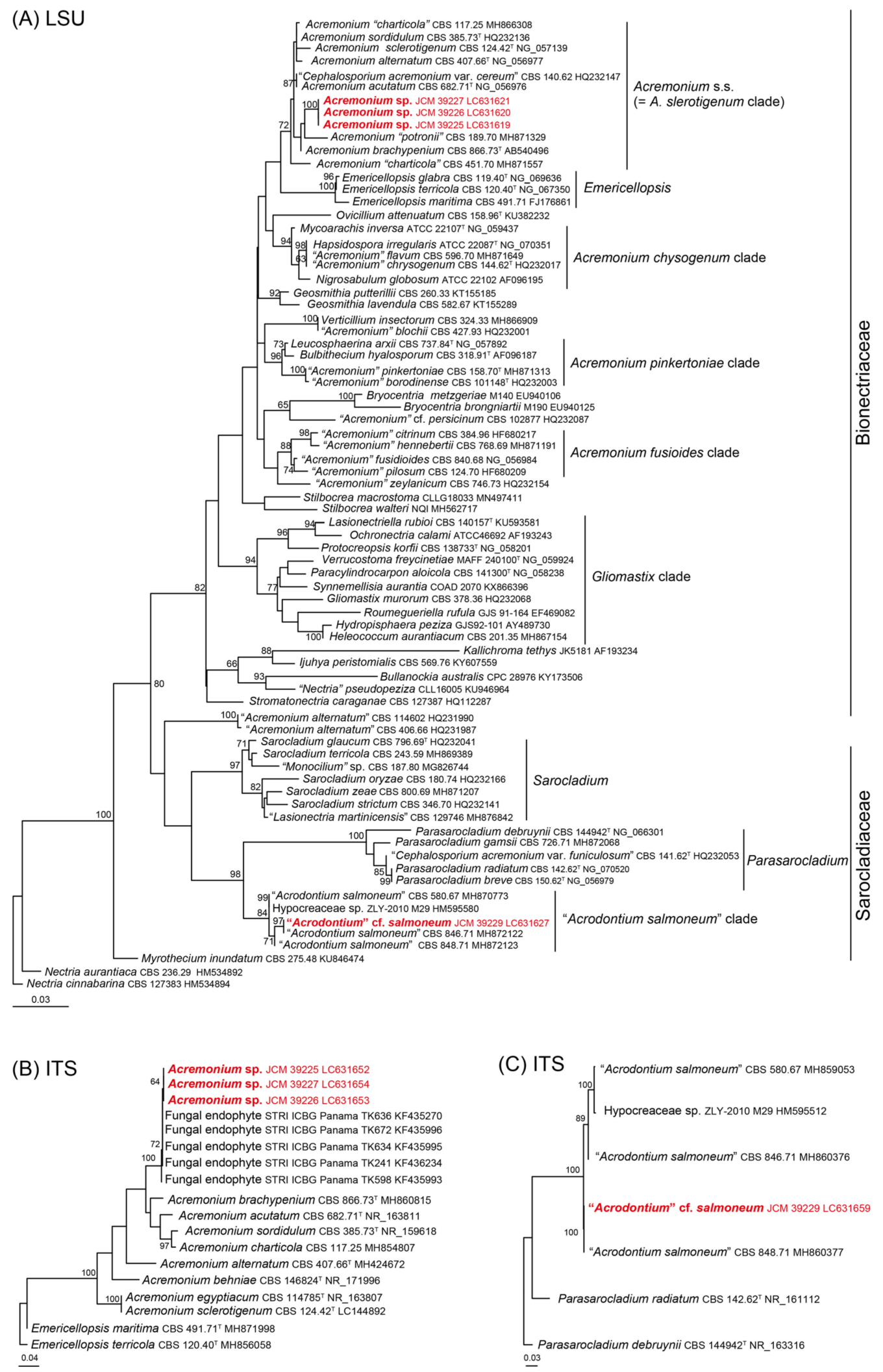

Figure 6. Maximum-likelihood (ML) tree of Bionectriaceae and Sarocladiaceae. (A) Species relationship of Bionectriaceae and Sarocladiaceae by TIM3e+I+G4 model based on the LSU sequences. (B) Species relationship of Acremonium spp. by TIM2e+G4 model based on the ITS sequences. (C) Comparison of environmental samples with "Acrodontium" salmoneum complex by TNe model based on the ITS sequences. Standard nonparametric bootstrap greater than or equal to $60 \%$ are presented at the nodes. Ex-type strains are indicated with a superscript T. The sequences in this study are shown in bold. The scale bar represents nucleotide substitution per site. 


\section{Discussion}

Previous studies of SCIF have focused on species diversity, host preference, physiological features, and isolates from mushrooms or sequestrate fungi [22,24,55,64]. Our study presented new information on the mycobiota of the ascomata of xylarialean fungi using direct observation and dilution plate methods. Several noteworthy microfungi were identified by focusing on their genetic, morphological, and ecological diversity. Acremonium, Acrodontium, and Simplicillium species and basidiomycetous yeasts were found (Table 2) and they were previously reported as SCIF by Gams et al. [8]. Some of these hypocrealean species have been reported as dominant SCIF groups on Tuber sp. $[23,24,55]$ and they are known as occurring on the old stroma of xylarialean fungi [31,32,65]. In contrast, helotialean or Trichoderma species were not isolated in this study. It may be due to an operational problem, such as isolating medium or seasonal and microenvironmental differences. Other species, such as polypores or corticioid mushrooms, were isolated probably from spores. Cerrena, Incrustoporia, Lenzites, Microporus, Neoantrodiella, Phlebia, Skeletocutis, and Trametes species are common decomposers of woody materials in forest ecosystems [66,67]. Phlebia livida and the Sistotrema brinkmanni complex are known to be distributed worldwide, including in Asia, Europe, North and South America, and Antarctica [68-70]. These species are known as wood-decaying mushrooms [69], although they are also assumed to be important decomposers under extremely low nutrient conditions [70]. These species seem to exist on the fungal surface as dispersed spores.

Fungal isolates occasionally could not be identified based on ITS sequences and morphological features, although species diversity of Acremonium, Acrodontium, Aspergillus, Penicillium, and Simplicillium have been well studied in previous studies $[47,56,61,71,72]$. Noteworthy species in the present study were identified as Acrodontium sp. 1, sp. 2, and sp. 3 aff. crateriforme, Acrodontium luzulae, "Acrodontium" cf. salmoneum, Acremonium sp., and Simplicillium sp. 1 and sp. 2 aff. sympodiphorum. We did not focus on Aspergillus and Penicillium species because these saprotrophic fungi are easily found on other substrates as well as decaying sporocarps.

Our investigation focused on enumerating SCIF using direct observations and dilution plate method. Common species, such as Acrodontium spp., Robbauera albescens, and Moesziomyces antarcticus, were isolated from an urban moist forest in the Sakuragawa area and urban dry forest in the Tsukuba area, but the overall species composition differed (Table 2). The species composition, in particular, was similar among the Tsukuba area but clearly differed among the Sakuragawa areas. Soil-borne fungi, such as Aspergillus, Beauveria, Penicillium, and Talaromyces, or basidiomycetes (mushrooms), were detected in the Tsukuba area compared to those in the Sakuragawa area. The xerophile decomposer fungi, such as Aspergillaceae, might predominantly colonize fungal tissue in the urban dry forest area. These geographical or environmental factors may also be associated with the species diversity of SCIF. Collado et al. [73] reported that environmental factors may affect the composition of fungal communities in endophytic fungi. To clarify the mycobiota of SCIF in detail, further studies are required to elucidate the effects of temperature and humidity.

This exploration of SCIF on Xylariales ascocarps revealed the mycobiota and its hidden diversity with the existence of several interesting species of microfungi. In particular, the existence of species complexes or different populations were implicated in Acrodontium and Simplicillium. From these genera, a potential antifungal substance such as acrodontiolamide (from "Acrodontium" salmoneum [74]) and simplicilliumtide (from Simplicillium obclavatum [75]) were reported. Identification and enumeration of SCIF should be investigated properly to elucidate the dynamics of the life cycle of fungicolous fungi, and this may also help in the discovery of novel bioactive substances.

Author Contributions: Conceived and designed the experiments: W.S.; Field Research: A.H. and W.S.; Performed the isolation experiments: W.S.; Performed the morphological observations: A.H. and W.S.; Performed the molecular analysis: A.H. and W.S.; Review and editing: A.H., W.S., G.O., M.O.; Supervision: M.O.; Wrote the paper: W.S. and A.H. All authors have read and agreed to the published version of the manuscript. 
Funding: This work was partially supported by the funds obtained from RIKEN Integrated Symbiology (iSYM) and JSPS KAKENHI (Grant Numbers 19H05689 to MO and 21K15155 to AH).

Data Availability Statement: The sequences generated in this study can be found in GenBank. The accession numbers of the sequences deposited in GenBank are: LC631614-LC631686.

Acknowledgments: The authors would like to thank the librarians of the RIKEN Library. We gratefully acknowledge the editors and the anonymous reviewers for constructive comments on the manuscript. The second author is grateful to Y. Takashima for providing valuable information on Bionectriaceae and T. Sato for helping with the collection of fungal samples and providing valuable comments for the paper.

Conflicts of Interest: The authors declare no conflict of interest. All the experiments undertaken in this study comply with the current laws of the country in which they were performed.

\section{References}

1. Hawksworth, D.L.; Lücking, R. Fungal diversity revisited: 2.2 to 3.8 million species. Microbiol. Spectr. 2017, 5. [CrossRef]

2. Grum-Grzhimaylo, A.A.; Georgieva, M.L.; Bondarenko, S.A.; Debets, A.J.M.; Bilanenko, E.N. On the diversity of fungi from soda soils. Fungal Divers. 2016, 76, 27-74. [CrossRef]

3. Le Calvez, T.; Burgaud, G.; Mahé, S.; Barbier, G.; Vandenkoornhuyse, P. Fungal diversity in deep-sea hydrothermal ecosystems. Appl. Environ. Microbiol. 2020, 75, 6415-6421. [CrossRef] [PubMed]

4. Sklenář, F.; Jurjević, Z.; Zalar, P.; Frisvad, J.C.; Visagie, C.M.; Kolař́ík, M.; Houbraken, J.; Chen, A.J.; Yilmaz, N.; Seifert, K.A.; et al. Phylogeny of xerophilic aspergilli (subgenus Aspergillus) and taxonomic revision of section Restricti. Stud. Mycol. 2017, 88, 161-236. [CrossRef]

5. Zalar, P.; de Hoog, G.S.; Schroers, H.J.; Frank, J.M.; Gunde-Cimerman, N. Taxonomy and phylogeny of the xerophilic genus Wallemia (Wallemiomycetes and Wallemiales, cl. et ord. nov.). Antonie van Leeuwenhoek 2005, 87, 311-328. [CrossRef]

6. Morgenstern, I.; Powlowski, J.; Ishmael, N.; Darmond, C.; Marqueteau, S.; Moisan, M.C.; Quenneville, G.; Tsang, A. A molecular phylogeny of thermophilic fungi. Fungal Biol. 2012, 116, 489-502. [CrossRef]

7. Sun, J.Z.; Liu, X.Z.; McKenzie, E.H.C.; Jeewon, R.; Liu, J.K.; Zhang, X.L.; Zhao, Q.; Hyde, K.D. Fungicolous fungi: Terminology, diversity, distribution, evolution, and species checklist. Fungal Divers. 2019, 95, 337-430. [CrossRef]

8. Gams, W.; Diederich, P.; Põldmaa, K. Fungicolous fungi. In Biodiversity of Fungi; Muller, G.M., Bills, G.F., Foster, M.S., Eds.; Academic Press: Amsterdam, The Netherlands, 2004; pp. 343-392. [CrossRef]

9. Jeffries, P. Biology and ecology of mycoparasitism. Can. J. Bot. 1995, 73, 1284-1290. [CrossRef]

10. Gilman, J.C.; Tiffany, L.H. Fungicolous Fungi from Iowa. Proc. Iowa Acad. Sci. 1952, 59, 99-110.

11. Seeler, E.V., Jr. Several fungicolous fungi. Farlowia 1943, 1, 119-133. [CrossRef]

12. Gams, W. Cephalosporium-like hyphomycetes: Some tropical species. Trans. Br. Mycol. Soc. 1975, 64, 389-404. [CrossRef]

13. Gams, W.; Zare, R. A revision of Verticillium sect. Prostrata. III. Generic classification. Nova Hedwigia 2001, 72, 329-337. [CrossRef]

14. Zare, R.; Gams, W.; Culham, A. A revision of Verticillium sect. Prostrata, I. Phylogenetic studies using ITS sequences. Nova Hedwigia 2000, 71, 465-480. [CrossRef]

15. Zare, R.; Gams, W. A revision of Verticillium section Prostrata. IV. The genera Lecanicillium and Simplicillium gen. nov. Nova Hedwigia 2001, 71, 1-50. [CrossRef]

16. Tubaki, K. Studies on the Japanese hyphomycetes (II) fungicolous group. Nagaoa 1955, 5, 11-40.

17. Porter, C.L. Concerning the characteristics of certain fungi as exhibited by their growth in the presence of other fungi. Am. J. Bot. 1924, 11, 168-188. [CrossRef]

18. Waksman, S.A. Associative and antagonistic effects of microorganisms. I. Historical review of antagonistic relationships. Soil Sci. 1936, 43, 51-68. [CrossRef]

19. Hoch, H.C.; Provvidenti, R. Mycoparasitic relationship: Cytology of the Sphaerotheca fuligena-Tilletiospis sp. interaction. Phytopathology 1979, 69, 359-362. [CrossRef]

20. Santos, A.F.D.; Dhingra, O.D. Pathogenicity of Trichoderma spp. on the sclerotia of Sclerotinia sclerotiorum. Can. J. Bot. 1982, 60, 472-475. [CrossRef]

21. Marletto, F. The micoflora of rhizosphere in truffle culture sites I. Truffle and rhizosphere yeast in truffle culture sites. Allionia 1969, 15, 155-171.

22. Buzzini, P.; Gasparetti, C.; Turchetti, B.; Cramarossa, M.R.; Vaughan-Martini, A.; Martini, A.; Pagnoni, U.M.; Forti, L. Production of volatile organic compounds (VOCs) by yeasts isolated from the ascocarps of black (Tuber melanosporum Vitt.) and white (Tuber magnatum Pico) truffles. Arch. Microbiol. 2005, 184, 187-193. [CrossRef] [PubMed]

23. Pacioni, G.; Leonardi, M. Truffle-inhabiting fungi. Soil Biol. 2016, 47, 283-299. [CrossRef]

24. Perlińska-Lenart, U.; Piłsyk, S.; Gryz, E.; Turło, J.; Hilszczańska, D.; Kruszewska, J.S. Identification of bacteria and fungi inhabiting fruiting bodies of Burgundy truffle (Tuber aestivum Vittad.). Arch. Microbiol. 2020, 202, 2727-2738. [CrossRef] [PubMed]

25. Danon, M.; Chen, Y.; Hadar, Y. Ascomycete communities associated with suppression of Sclerotium rolfsii in compost. Fungal Ecol. 2010, 3, 20-30. [CrossRef] 
26. Jones, E.E.; Stewart, A. Selection of mycoparasites of sclerotia of Sclerotinia sclerotiorum isolated from New Zealand soils. N. Z. J. Crop Hortic. Sci. 2000, 28, 105-114. [CrossRef]

27. Tu, J.C. Gliocladium virens, a destructive mycoparasite of Sclerotinia sclerotium. Am. Phytopathol. Soc. 1980, 70, 670-674. [CrossRef]

28. Whipps, J.M.; Budge, S.P. Screening for sclerotial mycoparasites of Sclerotinia sclerotiorum. Mycol. Res. 1990, 94, 607-612. [CrossRef]

29. Obase, K.; Douhan, G.W.; Matsuda, Y.; Smith, M.E. Culturable fungal assemblages growing within Cenococcum sclerotia in forest soils. FEMS Microbiol. Ecol. 2014, 90, 708-717. [CrossRef]

30. Petrini, L.; Petrini, O. Xylariaceous fungi as endophytes. Sydowia 1985, 38, 216-234.

31. Ellis, M.B.; Ellis, J.P. Microfungi on Miscellaneous Substrates; (Enlarged edition); The Richmond Publishing: Slough, UK, 1998.

32. Læssoe, T.; Peterson, J.H. Fungi of Temperate Europe; Princeton University Press: Princeton, NJ, USA, 2019.

33. Becker, K.; Lambert, C.; Wieschhus, J.; Stadler, M. Phylogenetic assignment of the fungicolous Hypoxylon invadens (Ascomycota, Xylariales) and investigation of its secondary metabolites. Microorganisms 2020, 8, 1397. [CrossRef]

34. Nordén, B.; Læssøe, T.; Jordal, J.B. Chlorostroma vestlandicum sp. nov., a host-specific mycoparasite on Hypoxylon vogesiacum from western Norway. Karstenia 2014, 54, 9-13. [CrossRef]

35. Vasilyeva, L.N.; Rogers, J.D.; Miller, A.N. Pyrenomycetes of the Great Smoky Mountains National Park. V. Annulohypoxylon and Hypoxylon (Xylariaceae). Fungal Divers. 2007, 27, 231-245.

36. Izumitsu, K.; Hatoh, K.; Sumita, T.; Kitade, Y.; Morita, A.; Tanaka, C.; Gafur, A.; Ohta, A.; Kawai, M.; Yamanaka, T.; et al. Rapid and simple preparation of mushroom DNA directly from colonies and fruiting bodies for PCR. Mycoscience 2012, 53, 396-401. [CrossRef]

37. White, T.J.; Bruns, T.; Lee, S.; Taylor, J. Amplification and direct sequencing of fungal ribosomal RNA genes for phylogenetics. In PCR Protocols: A Guide to Methods and Applications; Innis, M.A., Gelfand, D.H., Sninsky, J.J., Thomas, J.W., Eds.; Academic Press: San Diego, CA, USA, 1990; pp. 315-322.

38. Vilgalys, R.; Hester, M. Rapid genetic identification and mapping of enzymatically amplified ribosomal DNA from Several Cryptococcus species. J. Bacteriol. 1990, 172, 4238-4246. [CrossRef]

39. De Hoog, G.S.; Gerrits van den Ende, A.H.G. Molecular diagnostics of clinical strains of filamentous Basidiomycetes. Mycoses 1998, 41, 183-189. [CrossRef]

40. Gams, W.; van der Aa, H.A.; van der Plaats-Niterink, A.J.; Samson, R.A.; Stalpers, J.A. CBS Course of Mycology; Centraalbureau voor Shimmelcultures: Utrecht, The Netherlands, 1987.

41. Altschul, S.F.; Madden, T.L.; Schäffer, A.A.; Zhang, J.; Zhang, Z.; Miller, W.; Lipman, D.J. Gapped BLAST and PSI-BLAST: A new generation of protein database search programs. Nucleic Acids Res. 1997, 25, 3389-3402. [CrossRef]

42. Bensch, K.; Braun, U.; Groenewald, J.Z.; Crous, P.W. The genus Cladosporium. Stud. Mycol. 2012, 72, 1-401. [CrossRef]

43. Moncalvo, J.M.; Nilsson, R.H.; Koster, B.; Dunham, S.M.; Bernauer, T.; Matheny, P.B.; Porter, T.M.; Margaritescu, S.; Weiß, M.; Garnica, S.; et al. The cantharelloid clade: Dealing with incongruent gene trees and phylogenetic reconstruction methods. Mycologia 2006, 98, 937-948. [CrossRef]

44. Katoh, K.; Standley, D.M. MAFFT multiple sequence alignment software version 7: Improvements in performance and usability. Mol. Biol. Evol. 2013, 30, 772-780. [CrossRef]

45. Kumar, S.; Stecher, G.; Tamura, K. MEGA7: Molecular Evolutionary Genetics Analysis Version 7.0 for Bigger Datasets. Mol. Biol. Evol. 2016, 33, 1870-1874. [CrossRef]

46. Minh, B.Q.; Schmidt, H.A.; Chernomor, O.; Schrempf, D.; Woodhams, M.D.; von Haeseler, A.; Lanfear, R. Corrigendum to: IQ-TREE 2: New models and efficient methods for phylogenetic inference in the Genomic Era. Mol. Biol. Evol. 2020, 37, 1530-1534. [CrossRef]

47. Videira, S.I.R.; Groenewald, J.Z.; Braun, U.; Shin, H.D.; Crous, P.W. All that glitters is not Ramularia. Stud. Mycol. 2016, 83, 49-163. [CrossRef]

48. De Hoog, G.S. The genera Beauveria, Isaria, Tritirachium, and Acrodontium gen. nov. Stud. Mycol. 1972, 1, 1-41.

49. Perini, L.; Gostinčar, C.; Anesio, A.M.; Williamson, C.; Tranter, M.; Gunde-Cimerman, N. Darkening of the Greenland ice sheet: Fungal abundance and diversity are associated with algal bloom. Front. Microbiol. 2019, 10, 557. [CrossRef]

50. Koukol, O. What do we know about Acrodontium crateriforme? Mykologické Listy 2010, 111, 12-18.

51. Glenn, A.E.; Bacon, C.W.; Price, R.; Hanlin, R.T. Molecular phylogeny of Acremonium and its taxonomic implications. Mycologia 1996, 88, 369-383. [CrossRef]

52. Lucheta, A.R.; de Souza Cannavan, F.; Roesch, L.F.; Tsai, S.M.; Kuramae, E.E. Fungal community assembly in the Amazonian dark earth. Microb. Ecol. 2016, 71, 962-973. [CrossRef]

53. Manandhar, J.B.; Thapliyal, P.N.; Cavanaugh, K.J.; Sinclair, J.B. Interaction between pathogenic and saprobic fungi isolated from soybean roots and seeds. Mycopathologia 1987, 98, 69-75. [CrossRef]

54. He, P.; He, X.; Zhang, C. Interactions between Psilocybe fasciata and its companion fungus Acremonium strictum. Ecol. Res. 2006, 21, 387-395. [CrossRef]

55. Pacioni, G.; Leonardi, M.; Aimola, P.; Ragnelli, A.M.; Rubini, A.; Paolocci, F. Isolation and characterization of some mycelia inhabiting Tuber ascomata. Mycol. Res. 2007, 111, 1450-1460. [CrossRef]

56. Summerbell, R.C.; Gueidan, C.; Schroers, H.J.; de Hoog, G.S.; Starink, M.; Rosete, Y.A.; Guarro, J.; Scott, J.A. Acremonium phylogenetic overview and revision of Gliomastix, Sarocladium, and Trichothecium. Stud. Mycol. 2011, 68, 139-162. [CrossRef] [PubMed] 
57. Kozlova, E.V.; Mazina, S.E. Biodiversity of Fungi in the photic and aphotic zones of Montenegro caves. Aerobiologia 2020, 36, 589-604. [CrossRef]

58. Steiman, R.; Benoit-Guyod, J.L.; Guiraud, P.; Seigle-Murandi, F. Evaluation of acrodontiolamide, a chlorinated compound produced by Acrodontium salmoneum de Hoog for cytotoxicity and antimicrobial activity. Pharmazie 1995, 50, 693-695. [CrossRef]

59. Stejskal, V.; Hubert, J.; Kubátová, A. Associated-food-hazards: Storage fungi and mites in poppy, mustard, lettuce and wheat. Plant Prot. Sci. 2017, 38, 673-680. [CrossRef]

60. Yuan, Z.L.; Rao, L.B.; Chen, Y.C.; Zhang, C.L.; Wu, Y.G. From pattern to process: Species and functional diversity in fungal endophytes of Abies beshanzuensis. Fungal Biol. 2011, 115, 197-213. [CrossRef] [PubMed]

61. Nonaka, K.; Kaifuchi, S.; Ōmura, S.; Masuma, R. Five new Simplicillium species (Cordycipitaceae) from soils in Tokyo, Japan Mycoscience 2013, 54, 42-53. [CrossRef]

62. Serradilla, M.J.; Villalobos, M.D.; Hernández, A.; Martín, A.; Lozano, M.; Córdoba, M.D. Study of microbiological quality of controlled atmosphere packaged 'Ambrunés' sweet cherries and subsequent shelf-life. Int. J. Food Microbiol. 2013, 166, 85-92. [CrossRef]

63. Jaber, S.; Mercier, A.; Knio, K.; Brun, S.; Kambris, Z. Isolation of fungi from dead arthropods and identification of a new mosquito natural pathogen. Parasites Vectors 2016, 9, 491. [CrossRef]

64. Maurice, S.; Arnault, G.; Nordén, J.; Botnen, S.S.; Miettinen, O.; Kauserud, H. Fungal sporocarps house diverse and host-specific communities of fungicolous fungi. ISME J. 2021, 15, 1445-1457. [CrossRef]

65. Dennis, R.W.G. British Ascomycetes; J. Cramer: Vaduz, Liechtenstein, 1981.

66. Hattori, T. Diversity of wood-inhabiting polypores in temperate forests with different vegetation types in Japan. Fungal Divers. 2005, 18, 73-88.

67. Justo, A.; Miettinen, O.; Floudas, D.; Ortiz-Santana, B.; Sjökvist, E.; Lindner, D.; Nakasone, K.; Niemelä, T.; Larsson, K.H.; Ryvardeng, L.; et al. A revised family-level classification of the Polyporales (Basidiomycota). Fungal Biol. 2017, 121, 798-824. [CrossRef]

68. Greslebin, A.G.; Rajchenberg, M. Diversity of Corticiaceae sens. lat. in Patagonia, Southern Argentina. N. Z. J. Bot. 2003, 41, 437-446. [CrossRef]

69. Maekawa, N. Taxonomic study of Japanese Corticiaceae (Aphyllophorales) I. Rep. Tottori Mycol. Inst. 1993, 31, 1-149. [CrossRef]

70. Hao, Y.; Chen, S.Y.; Blanchette, R.A.; Liu, X.Z. Sistotrema brinkmannii, a psychrotolerant fungus from Antarctic soil. Mycosystema 2010, 29, 864-868.

71. Gräfenhan, T.; Schroers, H.J.; Nirenberg, H.I.; Seifert, K.A. An overview of the taxonomy, phylogeny, and typification of nectriaceous fungi in Cosmospora, Acremonium, Fusarium, Stilbella, and Volutella. Stud. Mycol. 2011, 68, 79-113. [CrossRef]

72. Samson, R.A.; Visagie, C.M.; Houbraken, J.; Hong, S.B.; Hubka, V.; Klaassen, C.H.W.; Perrone, G.; Seifert, K.A.; Susca, A.; Tanney, J.B.; et al. Phylogeny, identification and nomenclature of the genus Aspergillus. Stud. Mycol. 2014, 78, 141-173. [CrossRef]

73. Collado, J.; Platas, G.; Gonzalez, I.; Pelaez, F. Geographical and seasonal influences on the distribution of fungal endophytes in Quercus ilex. New Phytol. 1999, 144, 525-532. [CrossRef]

74. De Gusmáo, N.B.; Kaouadji, M.; Seigle-Murandi, F.; Steiman, R.; Thomasson, F. Acrodontiolamide, a chlorinated fungal metabolite from Acrodontium salmoneum. Spectrosc. Lett. 1993, 26, 1373-1380. [CrossRef]

75. Liang, X.; Nong, X.H.; Huang, Z.H.; Qi, S.H. Antifungal and antiviral cyclic peptides from the deep-sea-derived fungus Simplicillium obclavatum EIODSF 020. J. Agric. Food Chem. 2017, 65, 5114-5121. [CrossRef] 